\title{
Cerebrospinal fluid analysis differentiates between relapsing-remitting and secondary progressive multiple sclerosis
}

Peter J H Jongen, Karel J B Lamers, Wim H Doesburg, Wim A J G Lemmens, Otto R Hommes

\begin{abstract}
Objectives-To find whether CSF analysis may differentiate between relapsingremitting and secondary progressive multiple sclerosis.

Methods-In 17 patients with relapsingremitting and 16 patients with secondary progressive multiple sclerosis, all without current or recent relapses, albumin CSF: peripheral blood ratio, mononuclear cell number, CD4+, CD8+, and B1+ subsets, CD4+:CD8+ ratio, IgG, IgG index, IgM, IgM index, complement components $\mathrm{C} 3$ and $\mathrm{C} 4$, and $\mathrm{C} 3$ and $\mathrm{C} 4$ indices, myelin basic protein, neuron specific enolase, $\mathbf{S 1 0 0}$, and lactate were determined. For each measure the statistical distance measure $D^{2}$ was calculated. For computation of a discriminant score variables with a $P$ value $\leqslant 0.15$ were included (two sided univariate $t$ test). These were albumin CSF: peripheral blood ratio, mononuclear cell number, IgM, IgM index, C3, C4, neuron specific enolase, $\mathrm{S} 100$, and lactate. Simultaneous distributions of the variables were compared between both groups (multivariate $t$ test) and a discriminant score was computed (linear discriminant analysis).
\end{abstract}

Results-The discriminant score allocated all 14 relapsing-remitting patients to the relapsing-remitting group (positive score) and 12 of 13 secondary progressive patients to the secondary progressive group (negative score). One secondary progressive patient was allocated to the relapsing-remitting group.

Conclusions-Patients with relapsingremitting or secondary progressive multiple sclerosis differ in CSF profile and CSF analysis may help to differentiate between relapsing-remitting and secondary progressive multiple sclerosis.

(F Neurol Neurosurg Psychiatry 1997;63:446-451)

Keywords: multiple sclerosis; cerebrospinal fluid; discriminant analysis

Multiple sclerosis is a presumed autoimmune disease of the CNS with focal inflammation and demyelination as the major pathological features. The pathogenesis of CNS lesions consists of a series of events. Increased permeability of the blood-brain barrier enables mononuclear cells to enter the CNS parenchyma and to form perivascular infiltrates. ${ }^{12}$ The immune mechanisms then occurring involve $\mathrm{T}$ cells, macrophages, and antibodies. ${ }^{1-3}$ The inflammatory immune attack is thought to result in demyelination. ${ }^{4}$ Whereas inflammation is not necessarily associated with structural damage, demyelination leads to persistent deficits, producing a permanent interruption in axonal conduction. ${ }^{14}$ Later in the disease process axonal and glial damage also occur. ${ }^{15}$

Basically, these processes are reflected by changes in the composition of the CSF. Thus an increased CSF:peripheral blood ratio for albumin represents increased permeability of the blood-brain barrier (transudation), and raised mononuclear cell numbers in CSF reflect the cellular component of the inflammation. ${ }^{6}$ The presence of CSF specific oligoclonal bands and increased IgG and IgM indices indicate intrathecal immunoglobulin production. ${ }^{6}$ In addition, intrathecal activation of the complement system leads to altered CSF concentrations of the complement components $\mathrm{C} 3$ or $\mathrm{C} 4$ or their intrathecal synthesis. ${ }^{78}$ Increased CSF concentration of myelin basic protein mirrors demyelination. ${ }^{9}$ Myelin basic protein values are raised in patients with clinically active multiple sclerosis and fall significantly after methylprednisolone treatment. ${ }^{10}$ Neuron specific enolase is a marker for neuronal damage and CSF concentrations are increased in various disorders of the CNS. ${ }^{11-13}$ The nervous system specific S100 protein is notably present in astrocytes and oligodendrocytes, and CSF S100 is a marker for glial damage. ${ }^{11}{ }^{12}{ }^{14-16}$ In patients with multiple sclerosis S100 concentrations are higher during active disease. ${ }^{14}{ }^{15}$ Subsequently, the CSF lactate concentration increases as a result of intracerebral processes involving ischaemia. ${ }^{6}{ }^{17}$

Most patients with multiple sclerosis start with a relapsing-remitting course. After five to 10 years most patients gradually transgress to the secondary progressive phase. ${ }^{5}$ Histopathological and MRI evidence indicate that pathogenic and pathological differences exist between relapsing-remitting and secondary progressive multiple sclerosis. ${ }^{18} 19$ By contrast with the relapsing-remitting phase the progressive phase shows less evidence for an autoimmune process. ${ }^{5}$ Data from MRI and NMR spectroscopy show that the chronic progression is related to neuronal and axonal 
Table 1 Cerebrospinal fluid measures in relapsing-remitting (RR) and secondary progressive $(S P)$ patients

\begin{tabular}{|c|c|c|c|c|c|c|}
\hline & \multirow[b]{2}{*}{ Units } & \multicolumn{2}{|c|}{ Median values } & \multirow{2}{*}{$\begin{array}{l}\text { Reference } \\
\text { values }\end{array}$} & \multicolumn{2}{|c|}{$R R v S P$} \\
\hline & & $R R(n=17)$ & $S P(n=16)$ & & $D^{2}$ & $P$ value \\
\hline \multicolumn{7}{|l|}{ Transudation: } \\
\hline Albumin CSF:PB & & 4.3 & 5.0 & $1.8-7.0$ & 0.39 & 0.09 \\
\hline \multicolumn{7}{|l|}{ Cellular immunology: } \\
\hline Mononuclear cells & $\mu \mathrm{l}$ & 8 & 3 & $0-4$ & 0.61 & 0.03 \\
\hline CD4+ & $\%$ & 71 & 71 & $50-80$ & 0.03 & 0.63 \\
\hline CD8+ & $\%$ & 20 & 21 & $15-37$ & 0.004 & 0.86 \\
\hline CD4+/CD8+ & & 3.4 & 3.4 & $1-4$ & 0.001 & 0.96 \\
\hline $\mathrm{B} 1+$ & $\%$ & 3 & 3 & $0-5$ & 0.06 & 0.50 \\
\hline \multicolumn{7}{|l|}{ Humoral immunology: } \\
\hline $\operatorname{IgG}$ & $\mathrm{mg} / 1$ & 37 & 43 & $11-38$ & 0.11 & 0.36 \\
\hline IgG index & & 0.83 & 0.74 & $0.36-0.60$ & 0.09 & 0.79 \\
\hline $\operatorname{IgM}$ & $\mathrm{mg} / 1$ & 0.6 & 0.4 & $0.1-0.4$ & 0.36 & 0.10 \\
\hline IgM index & & 0.07 & 0.05 & $0.01-0.07$ & 0.27 & 0.15 \\
\hline Complement C3 & $\mathrm{mg} / \mathrm{l}$ & 2.0 & 2.2 & $0.9-6.7$ & 0.41 & 0.08 \\
\hline $\begin{array}{l}\text { Complement C3 } \\
\text { index }\end{array}$ & & 0.57 & 0.60 & $0.32-0.77$ & 0.004 & 0.86 \\
\hline Complement C4 & $\mathrm{mg} / 1$ & 1.3 & 1.5 & $0.6-3.5$ & 0.28 & 0.14 \\
\hline $\begin{array}{l}\text { Complement C4 } \\
\text { index }\end{array}$ & & 0.92 & 1.07 & $0.4-1.7$ & 0.04 & 0.58 \\
\hline \multicolumn{7}{|l|}{ Demyelination: } \\
\hline MBP & $\mu \mathrm{g} / 1$ & 0.6 & 0.5 & $0.2-1.2$ & 0.19 & 0.22 \\
\hline \multicolumn{7}{|l|}{ Neuronal damage: } \\
\hline \multirow{2}{*}{\multicolumn{7}{|c|}{ Glial damage: }} \\
\hline & & & & & & \\
\hline S100 & $\mu \mathrm{g} / 1$ & 1.5 & 1.2 & $0.7-2.0$ & 0.29 & 0.13 \\
\hline \multicolumn{7}{|l|}{ Metabolic change: } \\
\hline Lactate & $\mu \mathrm{mol} / 1$ & 1660 & 1785 & $1380-1900$ & 0.45 & 0.08 \\
\hline
\end{tabular}

Median values, reference values, and statistical distance $\mathrm{D}^{2}$ are given for each variable. $\mathrm{PB}=$ peripheral blood; $\mathrm{MBP}=$ myelin basic protein; NSE $=$ neuron specific enolase .

damage. $^{51819}$ In view of these differences, drugs that are effective in the relapsingremitting phase are not necessarily so in the secondary progressive phase, and drug research involves separate trials for relapsingremitting and secondary progressive multiple sclerosis. Thus the immunomodulating agent copolymer-1 has been shown to lessen disability in relapsing-remitting patients but was not effective in the chronic progressive phase..$^{20}$ As the number of immunotherapies is expected to increase in the near future, accurate distinction between relapsing-remitting and secondary progressive multiple sclerosis becomes more relevant, to optimise the application of possibly expensive drugs. Importantly, however, at a certain stage of the disease course various circumstances may seriously hinder the differentiation between relapsingremitting and secondary progressive multiple sclerosis-namely, clinical fluctuations in between relapses in the relapsing-remitting phase; the insidious character of the transgression to the secondary progressive phase; and the occurrence of stable periods in the secondary progressive phase. As a consequence, in individual patients the secondary progressive phase of the disease can often only be diagnosed reliably in retrospect.

Considering the above, we studied whether detailed CSF examination might differentiate between relapsing-remitting and secondary progressive multiple sclerosis. We measured a range of CSF variables in patients with clinically established relapsing-remitting or secondary progressive multiple sclerosis, and used discriminant analysis to develop an allocation index that distinguishes between the relapsing-remitting and secondary progressive type.

\section{Patients and methods}

PATIENTS

Thirty three patients were studied, 17 having been diagnosed as having relapsing-remitting disease and 16 as having secondary progressive disease on clinical grounds, in accordance with a recent consensus report. ${ }^{22}$ Inclusion criteria were (a) clinically definite multiple sclerosis, ${ }^{23}$ (b) for relapsing-remitting patients: two or more relapses in the preceding two years, and (c) for secondary progressive patients: at least six months of continuous progression in the year before the study, with or without relapses. Exclusion criteria were $(a)$ relapse in the three months before the study, (b) corticosteroid treatment in the two months before the study, (c) any previous immunosuppressive treatment, including cyclophosphamide, azathioprine, and cyclosporine $\mathrm{A}$, and $(d)$ contraindication for lumbar puncture. In each patient age, disease duration, number of relapses, and total methylprednisolone dose in the two years before the study were ascertained. In secondary progressive patients the duration of the secondary progressive phase was determined. On neurological examination one of us (ORH), an experienced neurologist, determined the expanded disability status scale (EDSS) score (24) with a 0.5 point interval-based on assessment of the neurological (Kurtzke) and the Scripps neurological rating scales (SNRS). ${ }^{25}$ The progression rate was calculated as the EDSS score:disease duration ratio. The study protocol was approved by the ethics committee of the University Hospital Nijmegen. Written informed consent was obtained from each patient.

\section{CEREBROSPINAL FLUID EXAMINATIONS}

Seven types of pathogenic or pathological processes were considered as potentially different between the relapsing-remitting and the secondary progressive phase of the disease: blood-brain barrier disturbance, cellular immune processes, humoral immune processes, demyelination, neuronal damage, glial damage, and metabolic changes. Measurements in CSF corresponding to these processes were albumin CSF:peripheral blood ratio, mononuclear cell number, $\mathrm{CD} 4+, \mathrm{CD} 8+$, and $\mathrm{B} 1+$ subset percentages, CD4+:CD8+ ratio, IgG, IgG index, IgM, IgM index, complement component C3, complement component C3 index, complement component C4, complement component $\mathrm{C} 4$ index, myelin basic protein, neuron specific enolase, S100, and lactate. Lumbar punctures were performed at level L5-S1 according to standard procedures with an atraumatic conical elliptic shaped spinal needle 22G $103 \mathrm{~mm}$ with introducer (Polymedic). All punctures were performed between 1100 and 1300 hours and about $10 \mathrm{ml}$ colourless CSF was obtained. Simultaneously, peripheral venous blood was drawn via cubital venapuncture. Cell counting and determination of lymphocyte subpopulations were immediately performed. For the remaining measurements paired samples of CSF and serum were stored at $-70^{\circ} \mathrm{C}$. The lymphocyte subsets were assayed by flow cytometry on a FACS II cell 
Table 2 Characteristics of study population

\begin{tabular}{lccc}
\hline & $\begin{array}{l}\text { Relapsing-remitting } \\
(n=17)\end{array}$ & $\begin{array}{l}\text { Secondary progressive } \\
(n=16)\end{array}$ & $\begin{array}{l}\text { Pvalue } \\
\text { t test }\end{array}$ \\
\hline M/F & $5 / 12$ & $8 / 8$ & \\
Age (y) & $36.2(8.1)$ & $40.2(7.5)$ & 0.15 \\
EDSS & $3.0(1.1)$ & $4.1(1.3)$ & 0.01 \\
Scripps NRS & $72.7(12.5)$ & $62.1(12.2)$ & 0.02 \\
Relapses in 2 years before study & $2.8(0.8)$ & $0.6(0.8)$ & 0.0001 \\
Disease duration (y) & $6.4(4.3)$ & $9.2(3.8)$ & 0.06 \\
Progression rate & $0.7(0.6)$ & $0.5(0.2)$ & 0.18 \\
Progressive phase (y) & & $3.9(1.9)$ & \\
\hline
\end{tabular}

EDSS = expanded disability status scale; NRS = neurological rating scale.

Values are given as mean (SD). sorter (Becton Dickinson, USA) according to a method described by Dux et al. ${ }^{26} \mathrm{CD} 3+, \mathrm{CD} 4+$ (helper-inducer cell), CD8+ (suppressorcytotoxic cell) and CD20+ (B1 cell) were analysed. Fluorescein labelled antibodies were purchased from Dakopatt (Denmark). For distinguishing lymphocytes from other cells (erythrocytes) the lymphocyte marker CD45 CYQ (IQP, Groningen, The Netherlands) was always included in each test. IgG, IgM, and albumin were determined by immunonephelometry on a COBAS FARA II apparatus (Hoffman La Roche, Switzerland) with the exception of CSF IgM, which was assayed by an enzyme linked immunosorbent assay (ELISA) method as described by Jongen et $\mathrm{al}^{27}{ }^{28}$ Complement components $\mathrm{C} 3$ and $\mathrm{C} 4$ were measured by immunonephelometry on a Hyland lasernephelometer using antiserum from Dakopatt (Denmark). ${ }^{27}$ Myelin basic protein was determined by a double antibody radioimmunoassay kit according to the instructions of the manufacturer (Diagnostic Systems Laboratories, Webster Texas, USA) ${ }^{29}$ Neuron specific enolase measurement was performed by an immunoluminometric assay on an LIA-MAT analyser according to the instructions of the manufacturer (Sangtec Medical, Sweden). Age related values for these CNS specific proteins in CSF in our laboratory have been published. ${ }^{30} \mathrm{~S} 100$ was determined by a double monoclonal antibody enzyme immunoassay according to the procedure published by Lamers et al. ${ }^{17}$ The index value of a distinct protein $=$ protein $\mathrm{CSF} \times$ albumin serum:protein serum $\times$ albumin CSF. Table 1 presents the reference values for CSF indices (P5-P95), as established in our laboratory.

STATISTICAL ANALYSIS

For the $18 \mathrm{CSF}$ variables univariate and multivariate statistical analyses were performed after logarithmic transformation. ${ }^{31}$ For each CSF variables (table 1) the median value was calculated for both groups (relapsing-remitting and secondary progressive) by interpolation from the cumulative sample distributions. To rank the indices after their discriminating power (between relapsing-remitting and secondary progressive) the usual statistical distance measure $\mathrm{D}^{2}$ was calculated,

$$
\mathrm{D}^{2}=\left(\left(\operatorname{mean}\left(\log (\mathrm{x})_{\mathrm{RR}}\right)-\operatorname{mean}\left(\log (\mathrm{x})_{\mathrm{SP}}\right)\right) / \mathrm{SD}_{\mathrm{p}}\right)^{2}
$$

with $\mathrm{SD}_{\mathrm{p}}$ being the pooled SD (after logarithmic transformation) over both groups.

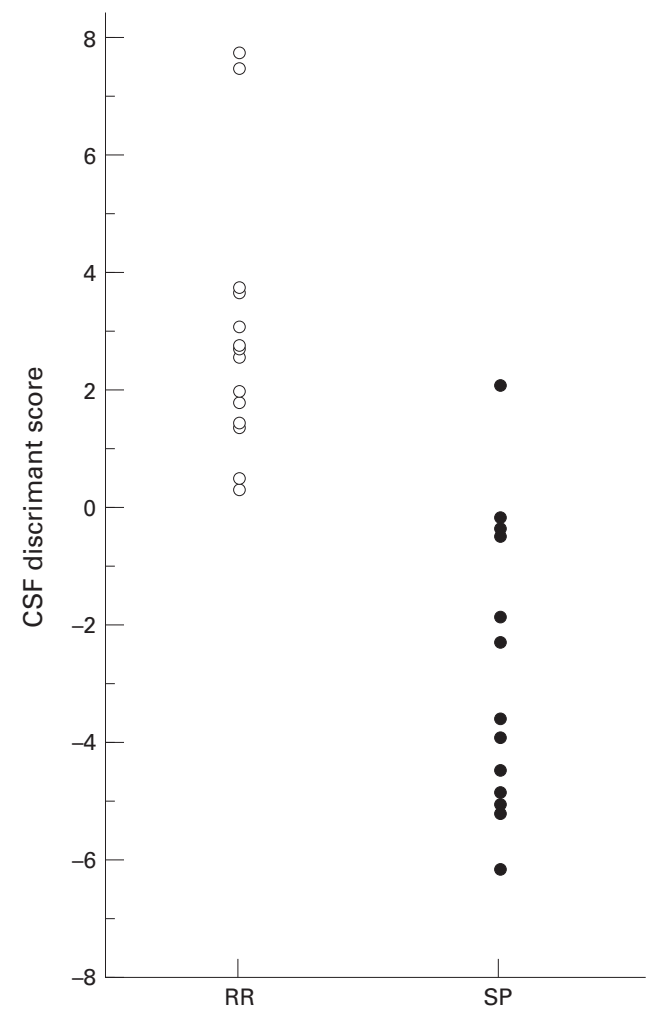

Figure 1 Cerebrospinal fluid discriminant score values in 17 patients with relapsing-remitting (RR) and 16 patients with secondary progressive (SP) multiple sclerosis.

For each variable the statistical comparison of the sample distribution between both groups was done by univariate two sample $t$ test (two sided $\alpha=0.05)$. For the computation of an allocation index (=discriminant score) we tried to use fewer variables. This was achieved by inclusion only of those variables for which the $\mathrm{P}$ value of the two sided univariate $t$ test was $\leqslant 0.15$. The simultaneous distributions of these variables were compared between both groups by means of the multivariate $t$ test (Hotelling's test). A discriminant score was computed according to the method of linear discriminant analysis (Fisher's equal probabilities). A second discriminant analysis was performed on those selected variables assumed to be determinable at routine laboratories.

\section{Results}

PATIENT CHARACTERISTICS

Table 2 shows patient characteristics. As a group secondary progressive patients had significantly higher EDSS scores, lower SNRS scores, and a lower number of relapses than relapsing-remitting patients. All but three patients - one relapsing-remitting and two secondary progressive- - had received methylprednisolone in the two years before the study, No patient had received prednisone in these years. The total methylprednisolone doses in the two years before the study did not differ significantly between relapsing-remitting and secondary progressive patients.

DISCRIMINANT ANALYSIS

Table 1 shows median values of CSF variables, reference values, $\mathrm{D}^{2}$ after logarithmic transfor- 
Table 3 Calculation of CSF discriminant scores in two patients

\begin{tabular}{|c|c|c|c|c|c|}
\hline Variable & Value & $\log$ & $\begin{array}{l}\text { Multiplication } \\
\text { factor }\end{array}$ & $\begin{array}{l}\text { Contribution to } \\
\text { discriminant score }\end{array}$ & Cumulative score \\
\hline \multicolumn{6}{|c|}{ Patient $A$} \\
\hline Intercept & & & & -5.95 & -5.95 \\
\hline $\mathrm{Q}$ albumin & 4.30 & 1.4586 & 14.37 & 20.96 & 15.01 \\
\hline MNC & 11.00 & 2.3979 & 1.15 & 2.75 & 17.76 \\
\hline $\operatorname{IgM}$ & 0.30 & -1.2040 & 6.13 & -7.38 & 10.37 \\
\hline IgM index & 0.07 & -2.6593 & -4.25 & 11.30 & 21.76 \\
\hline C3 & 1.70 & 0.5306 & -21.02 & -11.15 & 10.52 \\
\hline $\mathrm{C} 4$ & 0.60 & -0.5108 & -4.52 & 2.31 & 12.83 \\
\hline NSE & 7.10 & 1.9604 & 6.02 & 11.80 & 24.63 \\
\hline $\mathrm{S} 100$ & 0.66 & -0.4186 & 2.23 & -0.93 & 23.70 \\
\hline Lactate & 1832 & 7.5132 & -2.66 & -20.02 & 3.68 \\
\hline $\begin{array}{l}\text { Discriminant } \\
\text { score }\end{array}$ & & & & & +3.68 \\
\hline Allocation to RR & & & & & \\
\hline \multicolumn{6}{|c|}{ Patient B } \\
\hline Intercept & & & & & -5.95 \\
\hline $\mathrm{Q}$ albumin & 16.90 & 2.8273 & 14.37 & 40.63 & 34.68 \\
\hline MNC & 9.00 & 2.1972 & 1.15 & 2.52 & 37.19 \\
\hline $\operatorname{IgM}$ & 2.40 & 0.8755 & 6.13 & 5.37 & 42.56 \\
\hline IgM index & 0.10 & -2.3026 & -4.25 & 9.78 & 52.34 \\
\hline $\mathrm{C} 3$ & 7.00 & 1.9459 & -21.02 & -40.90 & 11.45 \\
\hline $\mathrm{C} 4$ & 3.20 & 1.1632 & -4.52 & -5.26 & 6.19 \\
\hline NSE & 5.23 & 1.6536 & 6.02 & 9.95 & 16.14 \\
\hline $\mathrm{S} 100$ & 0.71 & -0.3496 & 2.23 & -0.78 & 15.36 \\
\hline Lactate & 1971 & 7.5863 & -2.66 & -20.21 & -4.85 \\
\hline $\begin{array}{l}\text { Discriminant } \\
\text { score }\end{array}$ & & & & & -4.85 \\
\hline Allocation to SP & & & & & \\
\hline
\end{tabular}

MNC = Mononuclear cells $; \mathrm{C} 3=$ complement component $\mathrm{C} 3 ; \mathrm{C} 4=$ complement component $\mathrm{C} 4$ $\mathrm{NSE}=$ neuron specific enolase; $\mathrm{Q}$ albumin $=\mathrm{CSF}$ : peripheral blood albumin ratio.

mation, and $t$ test $\mathrm{P}$ values. Based on $\mathrm{P}$ values the following variables were selected for discriminant analysis: CSF:peripheral blood albumin ratio $(\mathrm{P}=0.09)$, mononuclear cell number $(\mathrm{P}=0.03), \operatorname{Ig} M(\mathrm{P}=0.10), \operatorname{Ig} M$ index $(\mathrm{P}=0.15)$, complement component $\mathrm{C} 3$ $(\mathrm{P}=0.08)$, complement component $\mathrm{C} 4$ $(\mathrm{P}=0.14)$, neuron specific enolase $(\mathrm{P}=0.12)$, $\mathrm{S} 100(\mathrm{P}=0.13)$, and lactate $(\mathrm{P}=0.08)$. Discriminant analysis resulted in a discriminant score (allocation index) composed of these nine variables. Using this score all 14 relapsing-remitting patients were allocated to the relapsing-remitting group (positive discriminant score), and 12 of 13 secondary progressive patients to the secondary progressive group (negative discriminant score). One secondary progressive patient was allocated to the relapsing-remitting group. Table 3 shows examples of calculation of discriminant scores. Figure 1 shows the discriminant scores for the 33 patients. Notably, inclusion of nine variables by means of a stepwise discriminant analysis (significance levels "entry" and "stay" both 0.15) - in which only patients were included with complete information on all variables - resulted in almost the same set of variables. Only lactate was replaced by myelin basic protein, probably due to leaving out five patients with missing values on lactate. A second discriminant analysis was performed on those selected variables assumed to be determinable at routine laboratories. This analysis included only the CSF variables CSF:peripheral blood albumin ratio, mononuclear cell number, $\operatorname{Ig} M, \operatorname{Ig} M$ index, and lactate. The scores of the secondary progressive group overlapped those of the relapsing-remitting group, as seven of the 13 secondary progressive patients had a score falling in the relapsing-remitting range (fig 2 ).

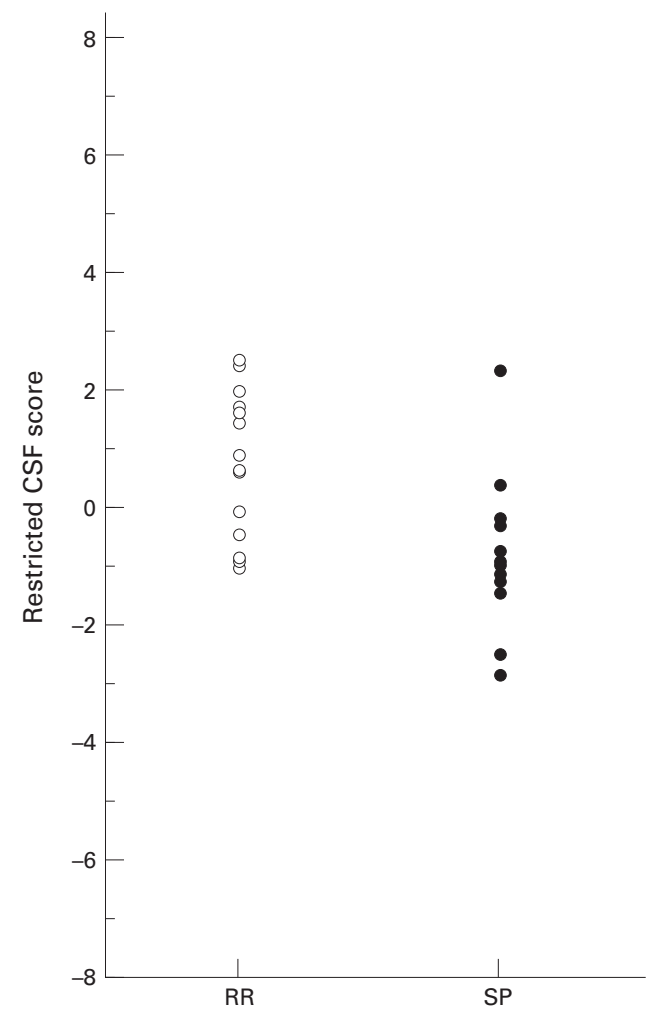

Figure 2 Values of a restricted CSF score in 17 patients with relapsing-remitting $(R R)$ and 16 patients with secondary progressive (SP) multiple sclerosis. Values were computed from variables considered to be determinable at routine laboratories (albumin ratio, mononuclear cell number, CSF IgM, IgM index, and CSF lactate).

\section{Discussion}

Recent reports underline the importance of CSF analysis in the differential diagnosis of CNS disorders. ${ }^{32}{ }^{33}$ The combination of several CSF measurements greatly improves the differential diagnosis of multiple sclerosis versus other neurological disorders and CSF analysis supports the diagnostic classification of multiple sclerosis. ${ }^{23}{ }^{34}$ We investigated whether detailed CSF analysis may differentiate between the relapsing-remitting and secondary progressive phase of the disease, and we performed a discriminant analysis of CSF variables in these patients. The variables studied reflected transudation, cellular and humoral immune processes, demyelination, neuronal and glial damage, and hypoxia. The discriminant score allocated 26 out of 27 patients to either the relapsing-remitting or secondary progressive group in agreement with the clinical diagnosis. This finding implies that patients diagnosed as having a relapsing-remitting or secondary progressive course on clinical grounds also differ with respect to CSF profile, and that the discriminant score may be of help in classifying individual patients as being relapsing-remitting or secondary progressive.

An important aspect of our study is that we only included relapsing-remitting patients who had had no current or recent clinical relapses. So our data are not confounded by abnormalities resulting from events related to exacerbation. On follow up the first exacerbations occurred at a mean of 137 (SD 103) days after 
CSF sampling, the earliest relapse occurring at 41 days, for which reason it is unlikely that CSF findings reflect a subclinical increase of disease activity.

Pathological and MRI studies in multiple sclerosis suggest that various pathogenic and pathological processes may be at work simultaneously. ${ }^{51819}$ Conceivably, the activity of each of these processes in the secondary progressive phase may be only slightly different from that in the relapsing-remitting phase, which means that for a given variable CSF concentrations in the secondary progressive phase may not differ significantly from those in the relapsing-remitting phase. For this reason we did not search for a single variable that might differerentiate between the two groups; nor did we try to detect significances for single variables. These might be found in large study populations, but, as expected, individual values largely overlap and are of little use as a discriminating tool. By contrast, our study was designed to detect changes in a complex CSF profile in a relatively small group of patients and thus to develop a discrimination index that may be used in individual patients. Thus we found that nine of the 18 variables tested $(50 \%)$ had a $P$ value $\leqslant 0.15$ and thus contributed to the discrimination index. As $\mathrm{CSF}$ measurement of neuron specific enolase, S100, and the complement components C3 and $\mathrm{C} 4$ may not be performed routinely in hospital laboratories, we determined the discriminating value of the CSF:peripheral blood albumin ratio, mononuclear cell number, $\operatorname{IgM}$, IgM index, and lactate. This second score seemed to be of limited use given that seven of the 13 secondary progressive patients had scores in the relapsing-remitting range.

The establishment of a relation between a clinical variable of multiple sclerosis and changes of CSF mononuclear cells, immunoglobulins or complement components is beset with difficulties, as immunotherapies may have long lasting effects on CSF immune indices. ${ }^{35}$ In our study no patient had received any cytotoxic agent, nor had recently used corticosteroids. Moreover, the total steroid dose in the two years before the study did not differ between relapsing-remitting and secondary progressive patients. For these reasons we think that we measured intrinsic differences and not treatment induced artifacts.

Generally, the relapsing-remitting patients had increased mononuclear cell numbers and $\operatorname{IgM}$, as well as neuron specific enolase and $\mathrm{S} 100$. The results for $\operatorname{IgM}$ in these patients seem not to reflect simple blood-brain barrier damage, as the IgM index tended to be higher than in secondary progressive patients. Secondary progressive patients generally had increased lactate and albumin with consequent increases of $\mathrm{C} 3$ and $\mathrm{C} 4$, the last probably due to blood-brain barrier damage rather than local synthesis, as the indices are normal. The significantly lower mononuclear cell numbers in the CSF of secondary progressive patients may indicate that the inflammatory component of the disease "burns out" during its natural course. Our findings on the albumin ratio tend to suggest that damage to the blood-brain barrier in the secondary progressive phase is rather more diffuse than the more striking punctate abnormalities which are seen in gadolinium MRI studies of the relapsing-remitting form. Others have also shown that the impairment of the blood-brain barrier in secondary progressive patients is worse than in relapsingremitting patients. ${ }^{36}$ For the finding that CSF IgM in secondary progressive patients tended to be lower than in relapsing-remitting patients (means $0.4 v 0.6, P=0.10$ ), Sindic et al reported a raised $\operatorname{IgM}$ index in $32 \%$ of 80 patients with multiple sclerosis, but in none of 10 patients with a history of multiple sclerosis exceeding 15 years. ${ }^{37}$ Two other studies registered raised IgM indices at a decreasing rate with an increasing duration of disease. ${ }^{38}{ }^{39}$ Although the lower IgM values in our secondary progressive patients may partly relate to duration of disease, the discriminant score was not related to disease duration (data not shown).

Concentrations of C4 in CSF made a large contribution to the differentiation index in that lower C4 is related to the relapsing-remitting course. As early as 1965 it was shown that CSF complement activity is lower in patients with multiple sclerosis than in controls, and the lowest during acute deterioration. ${ }^{40}$ Moreover, patients with raised CSF $\gamma$-globulin content showed lower complement activity than those with normal CSF $\gamma$-globulin, and the complement activity was significantly correlated with the total protein concentration in controls, but not in the patients with multiple sclerosis.$^{40}$ Recent CSF studies in patients with acute optic neuritis and multiple sclerosis confirmed previous reports on intrathecal complement activation. ${ }^{8}$ Therefore, we think that one explanation for the relatively low C4 concentrations in our relapsing-remitting group may be steady C4 consumption by immune mediated processes in between relapses. On the other hand, it is conceivable that $\mathrm{C} 4$ discrepancies reflect immunogenetic differences. In a recent study on complement gene polymorphisms Franciotta et al reported that patients with relapsingremitting multiple sclerosis have a significantly higher frequency of C4AQ0 (null) allele than primary progressive patients. ${ }^{41}$ Moreover, a structural gene deletion was present in $45 \%$ of relapsing-remitting patients with the $\mathrm{C} 4 \mathrm{AQ} 0$ allele. ${ }^{41}$ As complement factors contribute to elimination of immune complexes, deficiency of a functional complement component could predispose to multiple sclerosis, and more specifically to the occurrence of virus induced relapses.

The CNS tissue markers S100 and neuron specific enolase also contributed to the discriminant score, in that high CSF concentrations suggested relapsing-remitting diagnosis. As our patients were sampled in a relapse free period, this finding suggests that in between relapses tissue damage is more pronounced that in the progressive phase. Recently Massaro et al performed a five week follow up study of CSF changes during and after an exacerbation; S100 concentrations increased early after 
relapses and remained increased during the whole study period. ${ }^{15}$

To conclude, we calculated a discriminant score that differentiates between relapsingremitting and secondary progressive multiple sclerosis. From a pathogenic and pathophysiological point of view, our data indicate that a combination of cellular and antibody mediated, immune processes involving complement lead to damage of neurons and glia, and that these processes are more pronounced in relapsing-remitting than in secondary progressive multiple sclerosis. We speculate that monitoring of the discriminant score will prove useful in the early and accurate diagnosis of the secondary progressive versus the relapsingremitting phase in individual patients. However, as we included in our study only patients with an unquestionable clinical course, prospective studies are needed to validate the discriminant score and to assess its applicability in patients just transgressing from the relapsingremitting to the secondary progressive phase.

1 Adams CWM. The general pathology of multiple sclerosis: morphological and chemical aspects of the lesions. In:
Hallpike JF, Adams CWM, Tourtelotte WW, eds. Multiple Hallpike JF, Adams CWM, Tourtelotte WW, eds. Multiple
sclerosis. Pathology, diagnosis and management. London: sclerosis. Pathology, diagnosis and
Chapman and Hall, 1983:203-40.

2 Traugott U, Reinherz EL, Raine CS. Multiple sclerosis. Distribution of T-cell subsets, and Ia-positive macrophages in lesions of different ages. F Neuroimmunol 1983;4:201-21.

3 Lassmann H, Suchanek G, Ozawa K. Histopathology and the blood-cerebrospinal fluid barrier in multiple sclerosis. Ann Neurol 1994;36(suppl):S42-6.

4 Compston A. Remyelination of the central nervous system. Multiple Sclerosis 1996;1:388-92.

5 Minderhoud JM. On the pathogenesis of multiple sclerosis. A revised model of the cause(s) of multiple sclerosis, especially based on epidemiological data. Clin Neurol Neurosurg 1994;96:135-42.

6 Lamers KJB. Cerebrospinal fluid analysis. Metabolic, brain damage and immunologic aspects [thesis]. Nijmegen: 1996.

7 damage and immunologic aspects [thesis]. Nijmegen: 1996. A, Huraux JM. Intrathecal synthesis of proteins: from immunoglobulins to prealbumin. Ital f Neurol Sci 1992; (suppl 2):69-77.

8 Sellebjerg F, Garred P, Djialchivili I, Christansen M. Complement activation in acute optic neuritis and multiple sclerosis. $\mathcal{F}$ Neuroimmunol 1995; (suppl 1):50

9 Cohen SR, Brooks BR, Herndon RM, Jubelt B, McKhann GM. A diagnostic index of active demyelination: myelin basic protein in cerebrospinal fluid. Ann Neurol 1980;8:2531.

10 Frequin STFM, Barkhof F, Lamers KJB, Hommes OR, Borm GF. Cerebrospinal fluid myelin basic protein, IgG and IgM levels in 101 multiple sclerosis patients before and after treatment with high-dose intravenous methylprednisolone. Acta Neurol Scand 1992;86:291-7.

11 Mokonu K, Kato K, Kawai K, Matsuoka Y, Yanagi Y Neuron-specific enolase and S-100 protein in cerebrospinal fluid of patients with various neurological diseases. $f$ spinal fluid of patients with
Neurol Sci $1983 ; 60: 443-51$.

12 Persson L, Hardemark H-G, Gustafsson J, et al. S-100 protein and neuron-specific enolase in cerebrospinal fluid and serum: markers of cell damage in human central nervous system. Stroke 1987;18:911-8

13 Lamers KJB, van Engelen BGM, Gabreels FJM, Homme OR, Borm GF, Wevers RA. Cerebrospinal neuron-specific enolase, S-100 and myelin basic protein in neurological disorders. Acta Neurol Scand 1995;92:247-51.

14 Massaro AR, Michetti F, Laudisio A, Bergonzi P. Myelin basic protein and S-100 antigen in cerebrospinal fluid of patients with multiple sclerosis in the acute phase. Ital $\mathcal{F}$ Neurol Sci 1985;6:53-6.

15 Massaro AR, Carnevale P, Tonali P, Bock E. Glia cell pathobiology in multiple sclerosis detected by CSF markers. $\mathcal{F}$ Neurochem 1996;66(suppl 2):S28.

16 Sindic CJM, Chalon MP, Cambiaso CL, Depre A, Laterre EC, Masson PL. Assessment of damage to the central nervous system by determination of S-100 protein in the nervous system by determination of S-100 protein in the
cerebrospinal fluid. $\mathcal{F}$ Neurol Neurosurg Psychiatry 1982;45: cerebros $1130-5$.
17 Lamers KJB, Schoonderwaldt HC, Borkent MV, Theeuwes AGM, Doesburg WH, Wevers RA. The effect of acute cerebrovascular diseases on serum and cerebrospinal fluid parameters. Clin Neurol Neurosurg 1987;89:23-9.

18 Barnes D, Munro PM, Youl BD, Prineas JW, McDonald WI. The longstanding MS lesion. A quantitative MRI and electron microscopic study. Brain 1991;114:1271-80.

19 Sinnige LG, Teeuwissen E, Hew JM, Minderhoud JM. Correlation between magnetic resonance imaging and clinical paremeters in multiple sclerosis. Acta Neurol Scand 1995;91:188-91.

20 Johnson KP, Brooks BR, Cohen JA, et al. The Copolymer 1 Multiple Sclerosis Study Group. Neurology 1995;45:126876.

21 Bornstein MB, Miller A, Slagle S, et al. A placebocontrolled, double-blind, randomized, two-center, pilot trial of Cop 1 in chronic progressive multiple sclerosis. Neurology 1991;41:533-9.

22 Lublin FD, Reingold SC, for the National Multiple Sclerosis Society (USA) Advisory Committee on Clinical Trials of New Agents in Multiple Sclerosis. Defining the clinical course of multiple sclerosis: results of an international survey. Neurology 1996;46:907-11.

23 Poser CM, Paty DW, Scheinberg L, et al. New diagnostic criteria for multiple sclerosis: guidelines for research protocols. Ann Neurol 1983;13:227-31.

24 Kurtzke JF. Rating neurologic impairment in multiple sclerosis: an expanded disability status scale (EDSS). Neurology 1983;33:1444-52.

25 Sipe JC, Knobler, Braheny SL, et al. A neurologic rating scale (NRS) for use in multiple sclerosis. Neurology 1984;34:1368-72.

26 Dux R, Kindler-Rorhborn A, Lennartz K, Rajewski MF. Calibration of fluorescence intensities to quantity antibody binding surface determinants of cell subpopulations by flow cytometry. Cytometry 1991;12:422-8.

27 Jongen PJH, AMTh Boerbooms, KJB Lamers, Raes BCM, Vierwinden G. Diffuse central nervous system involvement in systemic lupus erythematosus: intrathecal synthesis of the fourth component of complement. Neurology 1990;40: 1593-6.

28 Jongen PJH, Daelmans HEM, Bruneel B, den Hartog MR. Humoral and cellular immunologic study of cerebrospinal fluid in a patient with Behçet encephalitis. Arch Neurol 1992;49:1075-8.

29 Cohen SR, Herndon RM, McKhann GM. Radioimmunoassay of myelin basic protein in spinal fluid. $N$ Engl $\mathcal{F}$ Med 1976;295:1455-7.

30 van Engelen BGM, Lamers KJB, Gabreels FJM, Wevers RA, van Geel WJA, Borm GF. Age-related changes of neuron-specific enolase, S-100 protein, and myelin basic protein concentrations in cerebrospinal fluid. Clin Chem 1992;38:813-6.

31 Keene ON. The log transformation is special. Stat Med 1995;14:811-9.

32 Motter R, Vigo-Pelfrey C, Kholodenko D, et al. Reduction of $\beta$-amyloid peptide 42 in the cerebrospinal fluid of patients with Alzheimer's disease. Ann Neurol 1995;38: 643-8.

33 Arai $\mathrm{H}$, Terajima $\mathrm{M}$, Miura $\mathrm{M}$, et al. Tau in cerebrospinal fluid: a potential diagnostic marker in Alzheimer's disease. Ann Neurol 1995;38:649-52.

34 Prosiegel M, Neu IS, Pelka RB, Fateh-Moghadam A. Multivariate analysis of the serum-cerebrospinal fluid-proteinrelation for the diagnosis of neurological diseases of the central nervous system. Acta Neurol Scand 1983;68:40512.

35 Uitdehaag BM, Nillesen WM, Hommes OR. Long-lasting effects of cyclophosphamide on lymphocytes in peripher blood and spinal fluid. Acta Neurol Scand 1989;79:12-7.

36 McLean BN, Zeman AZ, Barnes D, Thompson EJ. Patterns of blood-brain barrier impairment and clinical features in multiple sclerosis. I Neurol Neurosurg Psychiatry 1993;56: $356-60$.

37 Sindic CJ, Cambiaso CL, Depre A, Laterre EC, Masson PL. The concentration of $\operatorname{IgM}$ in the cerebrospinal fluid of neurological patients. F Neurol Sci 1982;55:339-50.

38 Forsberg P, Henriksson A, Link H, Ohman S. Reference values for CSF-IgM, CSF-IgM/S-IgM ratio, and IgM index, and its application to patients with multiple sclerosis and aseptic meningoencephalitis. Scand F Clin Lab Invest 1984;44:7-12.

39 Lolli F, Halawa I, Link H. Intrathecal synthesis of IgG, IgA, $\operatorname{IgM}$, and $\operatorname{IgD}$ in untreated multiple sclerosis and controls. Acta Neurol Scand 1989;80:238-47.

40 Kuwert E, Pette E, Firnhaber W, Mai K. Demonstration of complement in spinal fluid in multiple sclerosis. Ann NY Acad Sci 1965;122:429.

41 Franciotta D, Dondi E, Bergamaschi R, Piccolo G, Melzi-d'Eril GV, Cosi V, Cuccia M. HLA complement gene polymorphisms in multiple sclerosis. A study on 80 Italian patients. $\mathcal{f}$ Neurol 1995;242:64-8. 